\title{
Rancang Bangun Game Tradisional Adu Gasing dengan Plane Detection Augmented Reality
}

\author{
Dewi Tresnawati ${ }^{1}$, Rifa Ferdiansyah ${ }^{2}$ \\ Jurnal Algoritma \\ Sekolah Tinggi Teknologi Garut \\ J1. Mayor Syamsu No. 1 Jayaraga Garut 44151 Indonesia \\ Email : jurnal@sttgarut.ac.id \\ 1dewitresnawati@sttgarut.ac.id \\ 21606016@sttgarut.ac.id
}

\begin{abstract}
Abstrak - Bermain game merupakan salah satu kegiatan yang banyak diminati oleh hampir semua orang. Hal ini ditandai dengan munculnya game-game baru berbasis internet yang banyak dimainkan oleh hampir setiap kalangan. Perkembangan ini tentu menimbulkan dampak positif dan juga negatif. Salah satu dampak positif dari perkembangan game ini adalah mengasah keterampilan dalam berfikir serta menyusun strategi. Disamping dampak positif tersebut perkembangan game online ini membawa pengaruh negatif, salah satu nya yaitu masyarakat mulai melupakan game-game tradisional yang sudah berkembang sejak zaman dahulu, seperti game gasing. Untuk melestarikan game tradisional terutama gasing di zaman modern ini, diperlukan cara-cara pengenalan yang tepat agar dapat di terima oleh masyarakat luas. Seiring dengan perkembangan teknologi, maka pengenalan game gasing ini dapat dilakukan dengan menggunakan beberapa teknologi, diantaranya dengan teknologi Augmented Reality. Penelitian ini bertujuan untuk mengenalkan game gasing tradisional dengan menggunakan plane detection augmented reality. Metodologi yang digunakan dalam penelitian ini yaitu Multimedia Development Life Cycle. Penelitian ini menghasilkan aplikasi yang dapat memperkenalkan permainan tradisional melalui game augmented reality dimana objek yang dimainkan adalah gasing yang merupakan permainan tradisional. Dimana kontribusi penelitian ini dapat memberikan manfaat bagi perkembangan serta pelestarian game tradisional, yaitu permainan gasing.
\end{abstract}

Kata Kunci - Gasing; Game; Multimedia Development Life Cycle.

\section{PENDAHULUAN}

Pada perkembangan zaman modern ini, game merupakan salah satu kegiatan yang banyak diminati oleh setiap orang. Hal ini ditandai dengan munculnya game-game baru yang berbasis internet yang banyak dimainkan oleh hampir setiap kalangan. Perkembangan ini tentu menimbulkan dampak positif dan juga negatif. Salah satu dampak positif dari perkembangan game ini adalah mengasah keterampilan dalam berfikir serta mengisi waktu luang. Disamping dampak positif tersebut perkembangan game online ini membawa pengaruh negatif, salah satu nya yaitu masyarakat mulai melupakan game-game tradisional yang sudah berkembang sejak zaman dahulu, salah satunya adalah game gasing. Perantara untuk melestarikan game tradisional terutama gasing di zaman modern ini, diperlukan diperlukan cara-cara pengenalan yang tepat dan mampu di terima oleh masyarakat luas, karena buktinya masih banyak masyarakat modern yang tidak mengenal game gasing serta sudah sedikit orang yang memainkannya di zaman modern ini. Adapun Gasing ini memiliki nilai filosofis yang mendalam, keseimbangan dalam artian yang luas, seimbang jiwa raga, seimbang tata nilai[1]. Untuk itu dibutuhkan perantara alternatif untuk mengenalkan game tradisional gasing secara modern agar dapat mudah diterima oleh para penggunanya. 
Media untuk mengenalkan dan melestarikan game tradisional gasing saat ini masih menggunakan pengenalan secara langsung yang ternilai kurang efektif dan kurang menjadi daya tarik buat masyarakat modern saat ini yang lebih suka memainkan game di handphone. Dalam kondisi ini perlu adanya media alternatif lain agar dapat membantu mengenalkan dan melestarikan permainan tradisional-gasing ini. Salah satu teknologi yang sedang berkembang serta digunakan dalam mengenalkan serta digunakan sebagai media alternatif dalam memainkan permainan gasing yaitu teknologi Augmented Reality [2]. Tujuan utama dari augmented reality yaitu untuk menciptakan lingkungan baru dengan menggabungkan interaktivitas lingkungan nyata dan virtual secara real time sehingga pengguna merasa bahwa lingkungan yang diciptakan adalah nyata[3].

Terdapat beberapa penelitian sebelumnya yang dijadikan rujukan. Penelitian pertama membahas mengenai perancangan dan pembangunan sebuah game yang masih tradisional yaitu game adu gasing dalam platform android dengan hasil berupa game android adu gasing melawan Artificial Intelligence[4]. Penelitian kedua membahas mengenai game augmented reality Animal Quiz untuk anak 5-7 tahun[5]. Penelitian ketiga membahas mengenai sebuah aplikasi pengenalan komponen mikrokontroler berbasis android dengan platform AR Core[6]. Penelitian keempat membahas mengenai yang membahas mengenai aplikasi multimedia pembelajaran dalam mengenalkan sebuah komponen komputer berbasis multimedia yang bisa juga digunakan pada media plaform desktop[7]. Penelitian kelima membahas yang membahas mengenai aplikasi android mengenalkan rukun islam pada anak-anak[8]. Penelitian ini bertujuan untuk membuat game augmented reality bertemakan adu gasing dan melestarikan budaya game tradisional seperti gasing dengan konsep modern. Harapan dari hasil penelitian ini yaitu dapat dijadikan media dalam mengenalkan dan melestarikan game gasing tradisional kepada masyarakat [9].

\section{METODE PENELITIAN}

Metodologi pada penelitian yang dilakukan adalah menggunakan MDLC. Sesuai dengan tahapan pada MDLC untuk mempermudah memahami tahapan penelitian disajikan dalam bentuk Work Breakdown Structure (WBS).

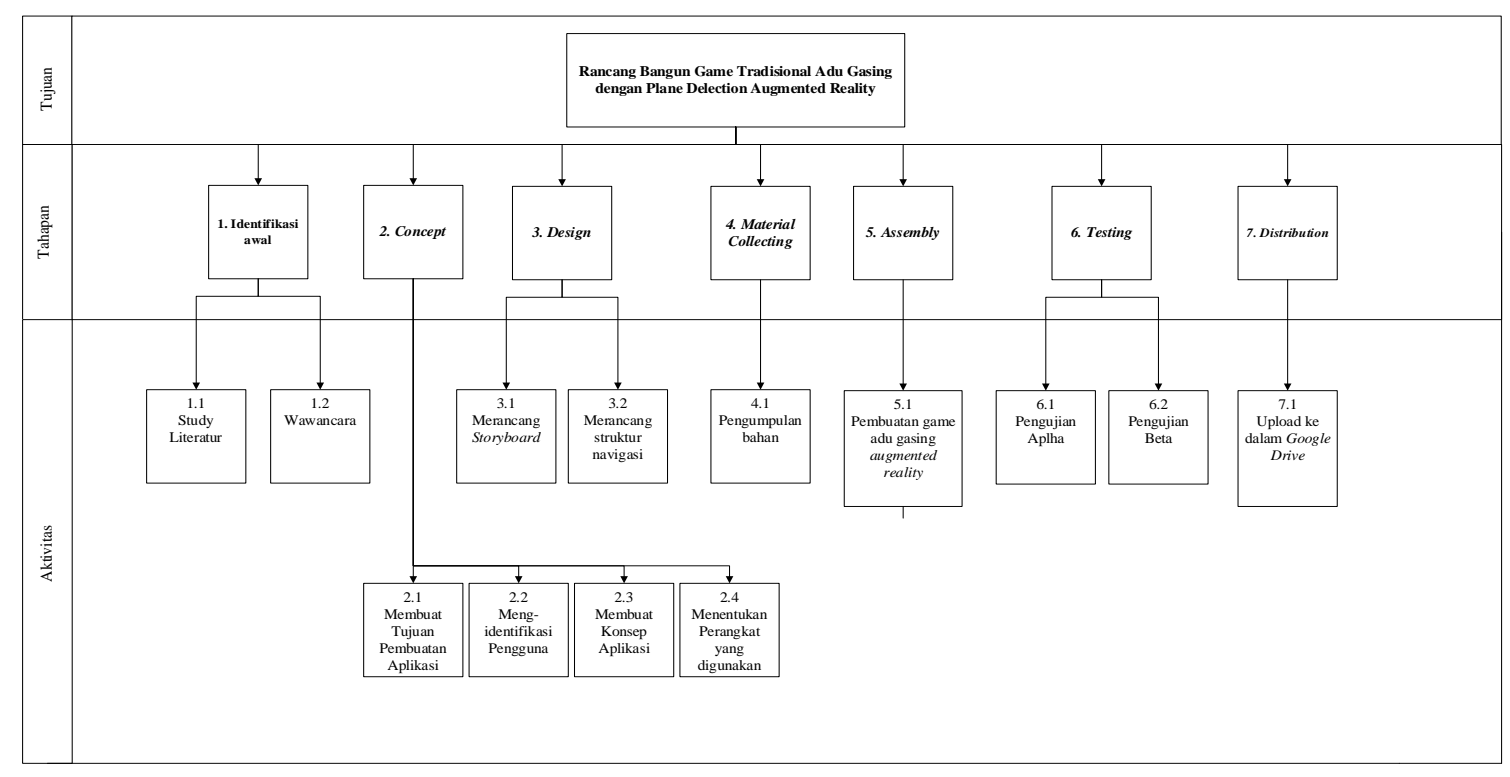

\section{Gambar 1: Work Breakdown Structure}

Penyajian WBS memberikan gambaran mengenai aktivitas dan sub aktivitas yang akan dilaksanakan pada penelitian ini. Berdasarkan gambar diagram Work Breakdown Structure tersebut, terdiri atas tahapan-tahapan serta aktivitas yang dilakukan dalam penelitian ini diantaranya adalah: 
1. Tahap Identifikasi awal

Didefinisikan identifikasi awal dalam penelitian berupa memahami konsep dan informasi terkait topik penelitian yang dijadikan sebagai landasan teori. Adapun aktvitas yang dilakukan yaitu:

a. Studi literatur

b. Wawancara

2. Tahap Concept

Didefinisikan untuk menentukan tujuan, siapa pengguna program aplikasi, bagaimana konsep game dan perangkat apa yang digunakan. Adapun aktvitas yang dilakukan yaitu:
a. Membuat tujuan pembuatan aplikasi
b. Mengidentifikasi pengguna
c. Membuat konsep aplikasi
d. Menentukan perangkat yang digunakan.

3. Tahap Design

Didefinisikan tahap membuat alur mengenai arsitektur program dan tampilan game. Adapun aktivitas yang dilakukan yaitu:

a. Merancang story board

b. Merancang struktur navigasi.

4. Tahap Material Collecting

Tahap pengumpulan bahan yang dilakukan sesuai kebutuhan aplikasi. Aktivitas yang dilakukan yaitu:
a. Mengumpulkan bahan gambar 2D
b. Mengumpulkan bahan modeling 3D.
c. Mengumpulkan bahan suara.
d. Mengumpulkan bahan effect.

5. Tahap Assembly

Tahap pembuatan dimana semua bahan digabungkan dengan kode didasarkan pada tahap design. Aktivitas yang dilaksanakannya adalah membuat game adu gasing augmented reality.

6. Tahap Testing

Dilakukan setelah selesai tahap pembuatan (assembly) dengan menjalankan game dan dilihat apakah ada kesalahan atau tidak pada game tersebut, aktivitas yang dilakukan yaitu:

a. Pengujian alpha.

b. Pengujian beta.

\section{Tahap Distribution}

Tahap menyebar luaskan game dengan menggunggah ke google drive lalu membagikan link google drive, sehingga pengguna game cukup mengunduhnya apabila ingin menggunakan game adu gasing augmented reality tersebut.

\section{HASIL DAN PEMBAHASAN}

\section{A. Hasil}

Aplikasi game augmented reality ini berisi game adu gasing dengan memanfaatkan system multiplayer agar bisa bermain online dua pemain yang dapat bertanding, ada game quiz, share, about, setting, pilih gasing, dan mengatur peletakan stadion pertandingan gasing, serta fitur game augmented reality mengenai pengenalan game gasing tradisional dengan konsep modern dengan menggunakan metodologi Multimedia Development Life Cycle (MDLC). 


\section{Identifikasi awal}

Pada tahapan pertama terdiri dari dua aktifitas yang dilakukan, yaitu melakukan studi literatur dan wawancara.

a. Hasil dari studi literatur ini adalah mengumpulkan berbagai macam informasi yang berkaitan dengan topik masalah yang sedang diteliti dan selanjutnya dijadikan sebagai dasar atau landasan teori yang digunakan dalam penelitian, melakukan pencarian penelitian sebelumnya yang digunakan sebagai referensi dalam penelitian kali ini.

b. Wawancara, dilakukan dengan mewawancarai pengguna game di kampung Tegal Gede sebanyak 10 responden dengan rincian 2 orang berasal dari developer, 2 orang siswa SD, 2 orang siswa SMP, 2 orang SMA, 2 orang mahasiswa yang akan dijadikan sebagai objek penelitian dalam mempelajari game gasing.

\section{Concept}

Pada tahap ini terdiri dari empat aktivitas yang dilakukan diantaranya membuat tujuan pembuatan aplikasi, mengidentifikasi pengguna, membuat konsep aplikasi, serta menentukan perangkat yang digunakan.

a. Tujuan penelitian ini untuk melestarikan permainan gasing. Aplikasi game gasing augmented reality ditujukan untuk masyarakat Kampung Tegal Gede, di dapat bahwa target game ini bersifat umum karena bersifat melestarikan permainan tradisional.

b. Identifikasi Pengguna. Aplikasi game gasing augmented reality ini bertujuan untuk membantu mengenalkan dan melestarikan game gasing tradisional kepada masyarakat modern.

c. Konsep Aplikasi. Berdasarkan dari tujuan penelitian yang dilakukan ini, didapatkan hasil mengenai kebutuhan fungsional aplikasi game yang akan dituliskan ke dalam deskripsi konsep aplikasi, yang disajikan dalam Tabel 1 berikut.

Tabel 1: Konsep Aplikasi

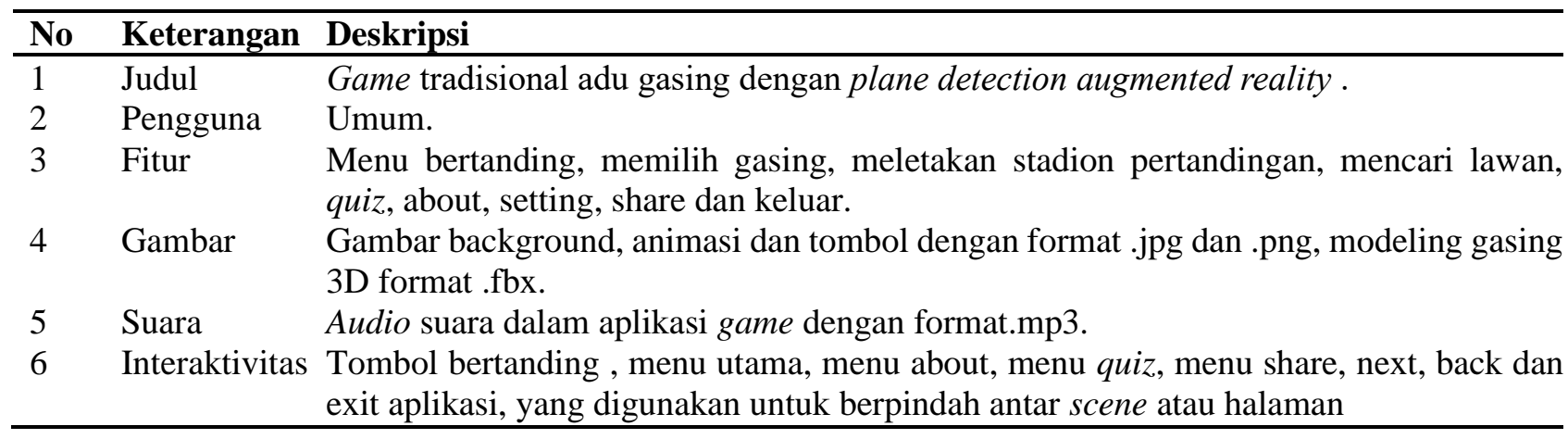

\section{Design}

Design (Perancangan) adalah komunikasi dalam bentuk visual yang menunjukkan bebrapa nilai dari proses hingga final desain. Nilai dalam perancangan komunikasi visual hadir pada setiap elemen desain yaitu: ilustrasi, tipografi, warna, dan layout[10].

a. Perangkat Yang Digunakan.

Adapaun perangkat yang nantinya digunakan sebagai media dalam aplikasi game gasing augmeted reality ini menggunakan smartphone android dengan spesifikasi versi android 9, agar pengguna dapat menjalankan fitur game adu gasing ini diperlukan android versi 7.1 ke atas, tapi untuk fitur lainnya masih bisa berjalan dengan lancar di versi 7.

b. Merancang Storyboard

Storyboard berperan sangat penting karena storyboard berfungsi sebagai pembatu dalam merancang multimedia supaya tersusun. Perancangan storyboard bertujuan untuk menggambarkan skenario secara keseluruhan atau dalam apa saja yang terjadi dalam aplikasi[11]. Berikut ini merupakan storyboard aplikasi yang disajikan dalam Tabel 5. 
Tabel 2: Storyboard Aplikasi

\begin{tabular}{|c|c|}
\hline Scene & Judul Scene \\
\hline Scene 1 & Halaman bertanding \\
\hline Scene 2 & Halaman pemilihan karakter \\
\hline Scene 3 & Halaman gameplay \\
\hline Scene 4 & Halaman lawan bot \\
\hline Scene 5 & Halaman pengaturan \\
\hline Scene 6 & Halaman kuis \\
\hline Scene 7 & Halaman bagikan \\
\hline Scene 8 & Halaman keluar \\
\hline
\end{tabular}

\section{Material collecting}

1) Gambar
a. Objek 2D

Tabel 3: Objek 2D

\begin{tabular}{|c|c|c|}
\hline Scene & Deskripsi & file objek 2D \\
\hline Scene 1 & Halaman Bertanding & background.jpg \\
\hline Scene 2 & Halaman Pemilihan karakter & background.jpg \\
\hline Scene 3 & Halaman Gameplay & - \\
\hline Scene 4 & Halaman Lawan Bot & - \\
\hline Scene 5 & Halaman Pengaturan & background.jpg \\
\hline Scene 6 & Halaman Kuis & $\begin{array}{l}\text { Next.png, Back.png, timerBG.png, stats.png, } \\
\text { backgrounds.png }\end{array}$ \\
\hline Scene 7 & Halaman Tentang & backgrounds.png \\
\hline Scene 8 & Halaman Bagikan & - \\
\hline Scene 9 & Halaman Keluar & - \\
\hline
\end{tabular}

Dari tabel di atas menejelaskan input data objek 2D di cari dulu lewat internet kemudian setelah dapat melakukan proses pembuatan dan pengeditan objek dan menghasilkan file objek format .png dan .jpg sesuai kebutuhan.

b. Objek 3D

Tabel 4: Objek 3D

\begin{tabular}{|c|c|c|}
\hline Scene & Deskripsi & file objek 3D \\
\hline Scene 1 & Halaman Bertanding & Spinning Top.fbx \\
\hline Scene 2 & Halaman Pemilihan karakter & $\begin{array}{l}\text { Spinner_Attacker_01, Spinner_Attacker_02, } \\
\text { Spinner_Defender_01, Spinner_Defender_02 }\end{array}$ \\
\hline Scene 3 & Halaman Gameplay & $\begin{array}{l}\text { Spinner_Attacker_01.fbx, Spinner_Attacker_02.fbx, } \\
\text { Spinner_Defender_01.fbx, Spinner_Defender_02.fbx, }\end{array}$ \\
\hline Scene 4 & Lawan Bot & Beystadium.fbx \\
\hline Scene 5 & Halaman Pengaturan & - \\
\hline Scene 6 & Halaman Kuis & - \\
\hline Scene 7 & Halaman Tentang & - \\
\hline Scene 8 & Halaman Bagikan & - \\
\hline Scene 9 & Halaman Keluar & - \\
\hline
\end{tabular}


Dari Tabel di atas menejelaskan input data objek 3D di cari dulu lewat internet kemudian setelah dapat melakukan proses pembuatan dan pengeditan disesuaikan dengan kebutuhan objek yang diinginkan dan menghasilkan file objek format .fbx.

2) Suara

Tabel 5: Suara

\begin{tabular}{rll}
\hline Scene & \multicolumn{1}{c}{ Deskripsi } & \multicolumn{1}{c}{ file suara } \\
\hline Scene 1 & Halaman Bertanding & metalSlap_v2.Mp3, clikbutton.Mp3 \\
Scene 2 & Halaman Pemilihan karakter & metalSlap_v2.Mp3, clikbutton.Mp3 \\
Scene 3 & Halaman Gameplay & metalSlap_v2.Mp3, clikbutton.Mp3 \\
Scene 4 & Halaman Lawan bot & metalSlap_v2.Mp3, clikbutton.Mp3 \\
Scene 5 & Halaman Pengaturan & metalSlap_v2.Mp3, clikbutton.Mp3 \\
Scene 6 & Halaman Kuis & metalSlap_v2.Mp3, clikbutton.Mp3, no.Mp3, yess.Mp3 \\
Scene 7 & Halaman Tentang & metalSlap_v2.Mp3, clikbutton.Mp3 \\
Scene 8 & Halaman Bagikan & metalSlap_v2.Mp3, clikbutton.Mp3 \\
Scene 9 & Halaman Keluar & - \\
\hline
\end{tabular}

Dari tabel di atas menejelaskan input suara di cari dulu lewat internet kemudian proses pengambilan dengan cara mendownload dan menghasilkan file .Mp3.

3) Teks

Tabel 6: Teks

\begin{tabular}{rll}
\hline Scene & \multicolumn{1}{c}{ Deskripsi } & file teks \\
\hline Scene 1 & Halaman Bertanding & Ethnocentric rg SDF \\
Scene 2 & Halaman Pemilihan karakter & Ethnocentric rg SDF \\
Scene 3 & Halaman Gameplay & LiberationSans SDF \\
Scene 4 & Halaman lawan bot & LiberationSans SDF \\
Scene 5 & Halaman Pengaturan & LiberationSans SDF \\
Scene 6 & Halaman Kuis & Ethnocentric rg SDF \\
Scene 7 & Halaman Tentang & AMCAP Eternal \\
Scene 8 & Halaman Bagikan & AMCAP Eternal \\
Scene 9 & Halaman Keluar & AMCAP Eternal \\
\hline
\end{tabular}

Dari tabel di atas input data teks di cari lewat internet kemudian melakukan proses pengambilan dengan cara mendownload dan hasilnya.

4) Animasi

Tabel 7: Animasi

\begin{tabular}{clll}
\hline Scene & \multicolumn{1}{c}{ Deskripsi } & & file animasi \\
\hline Scene 1 & Halaman Bertanding & Gasing \\
Scene 2 & Halaman Pemilihan karakter & Gasing 1, gasing 2, gasing3, gasing 4. \\
Scene 3 & Halaman Gameplay & Gasing & \\
Scene 4 & Halaman lawan bot & Gasing & \\
Scene 5 & Halaman Pengaturan & Tombol \\
Scene 6 & Halaman Kuis & Tombol & \\
Scene 7 & Halaman Tentang & - & \\
Scene 8 & Halaman Bagikan & - & \\
Scene 9 & Halaman Keluar & - & \\
\hline
\end{tabular}


Dari tabel di atas input data gambar di cari lewat internet kemudian melakukan proses pembuatan animasi dan coding dan hasilnya berupa animasi

\section{Assembly}

a. Proses implementasi gambar

Tahap pembuatan (Assembly) file assets gambar yang telah dibuat kemudian di Import kedalam project yang akan di buat pada aplikasi game Unity 2019.3 kemudian import to assets UI, maka gambar akan tersimpan pada assets project aplikasi game, seperti pada gambar 2.

b. Proses hasil implementasi pada gambar

Hasil Implementasi menggabungkan assets baik gambar, 3D Modeling, audio dan animasi yang sudah melewati proses sebelumnya, dengan software unity 2019.3 disatukan sampai menjadi aplikasi game yang sesuai dengan yang di rancang, seperti pada gambar 3.

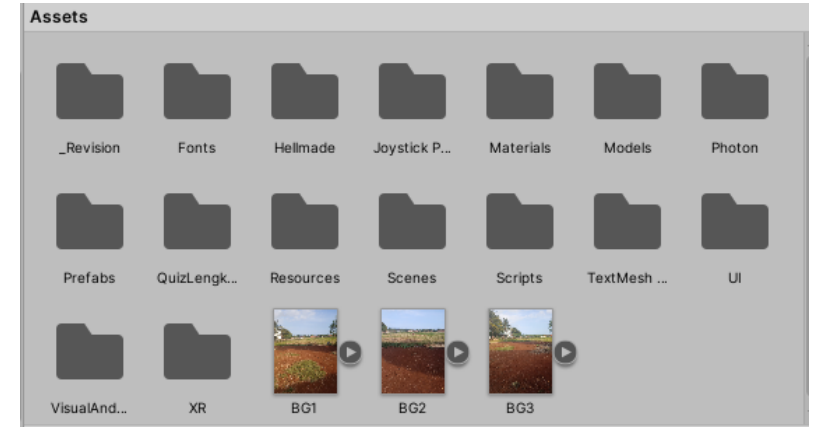

Gambar 2: File gambar yang digunakan pada aplikasi

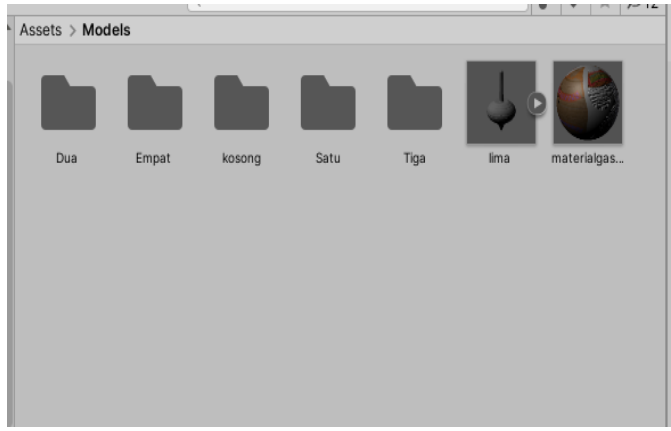

Gambar 3: Proses Hasil Implementasi

\section{Testing}

Tahap pengujian dilakukan dengan menggunakan dua metode pengujian, yaitu pengujian alpha untuk menguji keberfungsian dari aplikasi yang telah dibangun, serta pengujian beta untuk menguji sejauh mana aplikasi dapat diterima oleh pengguna

1) Alpha

Pada pengujian alpha meliputi dari menampilkan tiap scene halaman, fungsi tombol, dan audio yang dihasilkan. Pada pengujian alpha yang dilakukan pengembang menggunakan black box testing dengan hasil uji sukses semua.

2) Beta

Tahapan pengujian ini dilakukan secara objektif, yakni dengan aplikasi game diuji secara langsung oleh pengguna dari masyarakat kampung tegal gede dengan cara mencoba menggunakan aplikasi game kemudian menjawab beberapa pertanyaan seputar kenyamanan dan kelayakan game gasing augmented reality. Penyajian skala likert untuk sebuah pertanyaan, skor 5 untuk sangat baik, baik dengan skor 4 , cukup baik dengan skor 3 , tidak baik dengan skor 2, sangat buruk dengan skor 1 . Berikut pehitungannya [12]:

\section{T x Pn}

T : Total Jumlah panelis yang memilih

Pn : Pilihan angka skor likert

Penentuan sebuah interpretasi dari panelis terhadap cita rasa aplikasi game, menggunakan rumus:

Y : Skor tertinggi likert * jumlah panelis

$$
\text { index } \%=\frac{\text { Total Skor }}{Y} \times 100 \%
$$

Berdasarkan dari hasil nilai grand mean pada kenyamanan dan kemudahan dalam menggunakan aplikasi sebesar 98\% maka dari tabel kriteria interpretasi skor berdasarkan interval 98\% setara 
dengan sangat baik, maka diambil kesimpulan jika pengujian beta pada aplikasi game gasing augmented reality untuk pengenalan dan pelestarian game tradisional yang dikembangkan sudah memenuhi kebutuhan pengguna.

\section{Distribution}

Pada tahapan ini aplikasi game yang telah berhasil melewati lulus uji kemudian disimpan pada media penyimpanan google drive.

\section{B. Pembahasan}

Penelitian ini bertujuan untuk mengenalkan dan melestarikan game tradisional gasing dengan konsep modern. Berdasarkan output aplikasi yang memiliki beberapa fitur seperti fitur quiz yang berisi pengetahuan tentang gasing, pertandingan online multiplayer, diharapkan dapat mengenalkan gasing tradisional kepada masyarakat agar gasing tradisional tetap lestari dan mampu bertahan dengan mengadaptasinya kepada game modern dengan konsep augmented reality. Game ini dibangun dengan menggunakan beberapa perangkat pembantu seperti unity 2019.3, android studio, photonengine, dan assets aplikasi game gasing, untuk pembuatan aplikasi game gasing augmented reality.

\section{KESIMPULAN}

Penelitian ini telah berhasil membuat atau membangun aplikasi game gasing augmented reality berbasis android yang dapat menyelesaikan permasalahan penelitian serta membantu mengenalkan dan melestarikan game gasing tradisional di zaman modern ini dengan menerapkan augemented reality dengan menggunakan AR Core.

\section{DAFTAR PUSTAKA}

[1] E. Aras, Keseimbangan dalam keberagaman Gasing Indonesia. Jakarta: Direktorat Internalisasi Nilai dan Diplomasi Budaya, 2015.

[2] J. Grubert, T. Langlotz, S. Zollmann, and H. Regenbrecht, "Towards pervasive augmented reality: Context-awareness in augmented reality," IEEE Trans. Vis. Comput. Graph., 2017, doi: 10.1109/TVCG.2016.2543720.

[3] S. D. Yulianti, "Perancangan Apikasi Augmented Reality pembelajaran tata surya dengan mengunakan marker based tracking," Inform. Univ. Pemalang, vol. 3, no. 2541-1004, p. 1, 2018.

[4] I. Widarma Eka Putra, A. Agung Cahyawan Wiranatha, and I. Piarsa, "Rancang Bangun Game Tradisional 'Adu Gasing' Pada Platform Android,” Merpati, vol. 4, no. 2, pp. 178-187, 2017.

[5] B. N. Pelealu, T. Afirianto, and W. S. Wardhono, "Pengembangan Game Edukasi Mobile Augmented Reality untuk Membantu Pembelajaran Anak dalam Membaca, Menulis, dan Berhitung," J. Pengemb. Teknol. Inf. dan Ilmu Komput., vol. 3, no. 2, pp. 1492-1499, 2019.

[6] I. Huda and Y. Fuadi, "Penerapan Teknologi Augmented Reality Pada Aplikasi Media Pembelajaran Mikrokontoler Berbasis Android Dengan Platform AR Core," FAHMA, vol. 17, no. 1693-2277, p. 1, 2019.

[7] D. D. S. Fatimah, D. Tresnawati, and A. Nugraha, "Media Pembelajaran Pengenalan Komponen Komputer Berbasis Multimedia Dengan Pendekatan Metodologi (R\&D)," J. Algoritm., vol. 16, no. 2, pp. 173-180, 2020, doi: 10.33364/algoritma/v.16-2.173.

[8] D. Tresnawati, Y. Septiana, and A. Khofidin, "Aplikasi Edukasi Rukun Islam Untuk Anak dengan Pendekatan Multimedia Development Life Cycle," J. Algoritm., vol. 16, no. 2, pp. 166-172, 2020, doi: 10.33364/algoritma/v.16-2.166.

[9] D. Gudoniene and D. Rutkauskiene, "Virtual and augmented reality in education," Balt. J. Mod. 
Comput., 2019, doi: 10.22364/bjmc.2019.7.2.07.

[10] A. Setiawan, "Pencapaian Sense of Design Dalam," Andharupa, vol. Vol 02, no. 02, pp. 105-115, 2016.

[11] D. Tresnawati, E. Satria, and Y. A. Nugraha, "Pengembangan Aplikasi Komik Hadits Berbasis Multimedia," Algoritma, p. 9, 2016.

[12] Sugiono, Metode Penelitian Kuantitatif Kualitatif dan R\&D. Bandung: Alfabeta, 2012. 